\title{
Current diagnostic tools and management modalities of Nocardia keratitis
}

\author{
Mohammad Soleimani ${ }^{1}$, Ahmad Masoumi ${ }^{1}$, Sadegh Khodavaisy ${ }^{2}$, Mostafa Heidari ${ }^{1}$, Ali A. Haydar ${ }^{1}$ and \\ Alireza Izadi2 ${ }^{2 *}$ (D)
}

\begin{abstract}
Nocardia species are an uncommon but important cause of keratitis. The purpose of this review is to discus previous published papers relation to the epidemiology, etiology, diagnosis and management of Nocardia keratitis. Nocardia asteroides is the most frequently reported from Nocardia keratitis. Pain, photophobia, blepharospasm and lid swelling are mainly clinical manifestations. Usual risk factors for Nocardia keratitis are trauma, surgery, corticosteroids, and contact lens wear. Several antibiotics were used for treatment of Nocardia infection but according to studies, topical amikacin is the drug of choice for Nocardia keratitis. Topical steroid should not prescribe in these patients. In conclusion, although Nocardia keratitis is rare, early diagnosis and treatment are essential to prevent any scar formation and preserve a good visual acuity.
\end{abstract}

Keywords: Nocardia, Keratitis, Corneal ulcer, Confocal microscopy, Amikacin, Keratoplasty, Actinomycetes, Ocular trauma

\section{Background}

Nocardia species are Gram-variable, obligate aerobic, non-motile, branching, beaded filamentous, weakly acidfast bacilli, of the family Actinomycetaceae. Nocardia are ubiquitous soil saprophytes that are transmitted by either airborne or direct cutaneous inoculation route [1].

Nocardia are a rare cause of infectious keratitis. The diagnosis of Nocardia keratitis is challenging because they are not commonly encountered in clinical practice and mainly mimic fungal keratitis [2]. Typically, patients present after being treated with multiple empiric antibiotics for bacterial and/or fungal keratitis which may not have an appropriate effect on Nocardia species. Thus, delayed diagnosis and exacerbated ocular complications are common. Topical corticosteroids were associated with worse visual outcomes [3]. Nocardia keratitis clinical presentation includes ocular pain-out of proportion to exam-photophobia, blepharospasm, and eyelid edema. The slit-lamp examination reveals a classic wreath-like

\footnotetext{
* Correspondence: alirezaizadi81@yahoo.com

${ }^{2}$ Department of Medical Parasitology and Mycology, School of Public Health,

Tehran University of Medical Sciences, Tehran, Iran

Full list of author information is available at the end of the article
}

stromal infiltrates with satellite lesions $[4,5]$. Historically, sulfonamides like sulfacetamide and sulfamethoxazoletrimethoprim were used to treat Nocardia keratitis. Currently, the first-line treatment of Nocardia keratitis is topical amikacin [6].

\section{Main text}

A review of the literature conducted based on the database sources such as MEDLINE, web of scence, Scopus, PubMed and Google scholar from 2000 up to now. We searched all valuable and relevant information considering the epidemiology, etiology, diagnosis and management of Nocardia keratitis. The following keywords were used: Nocardia, keratitis, corneal ulcer, confocal microscopy, amikacin, keratoplasty, actinomycetes, and ocular trauma.

\section{Bacteriology}

The genus Nocardia is an aerobic Actinomycete known to cause disseminated and focal infections in humans. Nocardia was first described in 1888 by Edmond Nocard, a veterinarian, who isolated the organism from a cattle with bovine farcy [1]. In 1889, Trevisan named 
this strain as Nocardia farcinica [6]. Nocardia asteroides was isolated from a human brain abscess by Eppinger, in 1890, who named it Claothrix asteroides and subsequently was renamed as Nocardia asteroides by Blanchard in 1896 [7]. Recently, Conville et al. reviewed the taxonomy of Nocardia. The authors counted 92 recognized species of the Nocardia genus of which 54 species are clinically significant [7]. The following species were isolated from ocular tissues: $N$. abscessus, $N$. amikacinitolerans, $N$. amamiensis, $N$. beijingensis, $N$. brasiliensis, $N$. cyriacigeorgica, $N$. farcinica, N. exalbida, N. kruczakiae, N. otitidiscaviarum, $N$. puris, $N$. shinanonensis, $N$. transvalensis, and $N$. thailandica [7]. Nocardia asteroides is the most frequently Nocardia taxon isolated from human specimens [8].

\section{Epidemiology}

Nocardia spp. has been considered as a relatively rare cause of bacterial keratitis in recent years [6]. Current knowledge about the incidence of Nocardia keratitis is based on sporadic case reports and case series from various countries [3, 9]. Previous studies from Nepal [10], India (Heydarabad) [11] and India (Tamil Nadu) [12] reported that Nocardia constituted $0.3 \%, 1.7 \%$ and $4.2 \%$ of all bacterial isolates from cases of keratitis respectively.

\section{Risk factors}

Trauma is the most common predisposing factor for Nocardia keratitis [5]. The other usual risk factors are surgery, corticosteroids, and contact lens wear [5]. Javadi et al. reported an outbreak of Nocardia keratitis post photorefractive keratectomy (PRK) in 4 eyes operated by one surgeon, the same day [13]. Inadequate sterilization was concluded as the most probable cause of the outbreak. Many studies have described Nocardia keratitis post PRK and laser in situ keratomileusis (LASIK) [14, 15]. Troumani et al. documented a case of $N$. abscessus keratitis following a vegetal trauma [16]. Multiple case reports have identified the chronic wearing of contact lens as a predisposing factor for Nocardia keratitis (N. arthritidis [17], $N$. amikacinitolerans [1], N. farcinica [18], and N. exalbida [19]). Bharathi et al. studied 31 patients with Nocardia keratitis in south India and found that corneal injuries with soil and sand, agricultural works, corneal loose sutures, previous ocular surgery, and living in rural areas are the most important risk factors for Nocardia keratitis [20]. The authors found a male predominance. Another study reported a corneal ulcer with $N$. nova 48 days after uncomplicated cataract surgery [21]. The authors treated the ulcer successfully with oral co-trimoxazole and topical amikacin and moxifloxacin. Corticosteroid usage is another predisposing risk factor for Nocardia keratitis. A two-week treatment course of topical prednisolone acetate $1 \%$, after endothelial corneal graft rejection, was complicated by $N$. asteroides keratitis [22]. This corticosteroid induced ulcer was successfully treated with topical amikacin and ofloxacin. Other predisposing factors for Nocardia keratitis include diabetes (N. brasiliensis) [23], penetrating corneal injury [24] and travelling to Asia (N. transvalensis) [25].

\section{Clinical examination \\ Clinical manifestations}

Nocardia keratitis presents with pain, photophobia, blepharospasm, and lid swelling [6]. The clinical course is usually slow, and the patient has good visual acuity at presentation [26]. Fine papillary reaction may exist on the conjunctiva. The slit-lamp examination shows a patchy, white, pin-head infiltrates in the anterior corneal stroma arranged in a wreath-like pattern (Fig. 1) [17]. A mid-peripheral and paracentral or central corneal epithelial defect (CED) associated with stromal edema can be seen [27]. Stromal melting with fluffy and feathery margins can mimics fungal keratitis [15]. Additional associated findings include moderate anterior chamber reaction, hypopyon, satellite lesions, Descemet folds, and diffuse keratic precipitates (KPs) [22]. Mittal et al. reported a case of Nocardia sclerokeratitis presented with anterior stromal plaque-like infiltrations, conjunctival injection, and limbal thickening [28]. The feathery margins of the ulcer mimicked fungal keratitis. Smear and culture revealed Nocardia species [28]. Jain et al. described a case of Nocardia keratitis induced by topical prednisolone acetate $1 \%$ [22]. The following signs appeared after 2 weeks of corticosteroids treatment: conjunctival congestion, graft edema with Descemet folds, white patchy granular superficial infiltrates in the supranasal cornea, and a $1 \mathrm{~mm}$ hypopyon. Smear and culture exhibited thin, Gram positive, beaded branching filaments characteristic of Nocardia asteroids [22].

\section{Confocal microscopy}

Confocal microscopy is a non-invasive, in vivo modality useful in evaluating normal and pathologic cornea. This device benefits from a lateral resolution of $1 \mu \mathrm{m}$ and a depth of field of $10 \mu \mathrm{m}$. In addition to Nocardia keratitis, acanthamoeba and fungal keratitis can also be detected by confocal microscopy. Bacteria are not detected by confocal microscopy because of their small size, however, Nocardia can be seen due to their filamentous structure. Nocardia will appear as multiple, thin $(<$ $1 \mu \mathrm{m})$, short, beaded filamentous structures with right angled branching (Fig. 2) [29]. The round to oval bright structures surrounding the organism represent inflammatory cells. The hyperreflective filaments of Nocardia are thinner than fungal hyphae and are best visualized at the margins of the infiltrates $[14,30]$. 

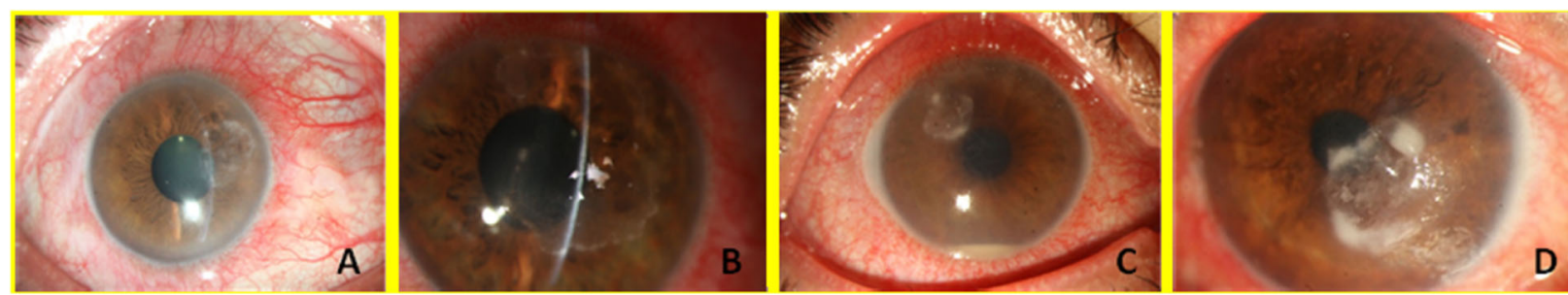

Fig. 1 Nocardia keratitis (a, b, c and d). Typical superficial patchy, white and pin-head infiltrates in a wreath-like pattern. Active lesion margins are seen

\section{Diagnostic methods Laboratory diagnosis}

The diagnosis of Nocardia keratitis is often delayed and complicated by long-term inappropriate treatments which lead to corneal scarring and poor visual acuity. Precise history taking and succinct clinical examination can prompt the diagnosis before any laboratory diagnostic evaluation. Good communication between physician and microbiologist is crucial for obtaining and transferring the samples properly and making an accurate diagnosis. The corneal ulcer should be scraped by a spatula or blade for smear and culture preparations [5]. Avoid sampling the conjunctiva and eyelid margins-which exhibit normal flora-is crucial for correct diagnosis [31]. Repeated scrapping should be collected for at least three smears and inoculation of

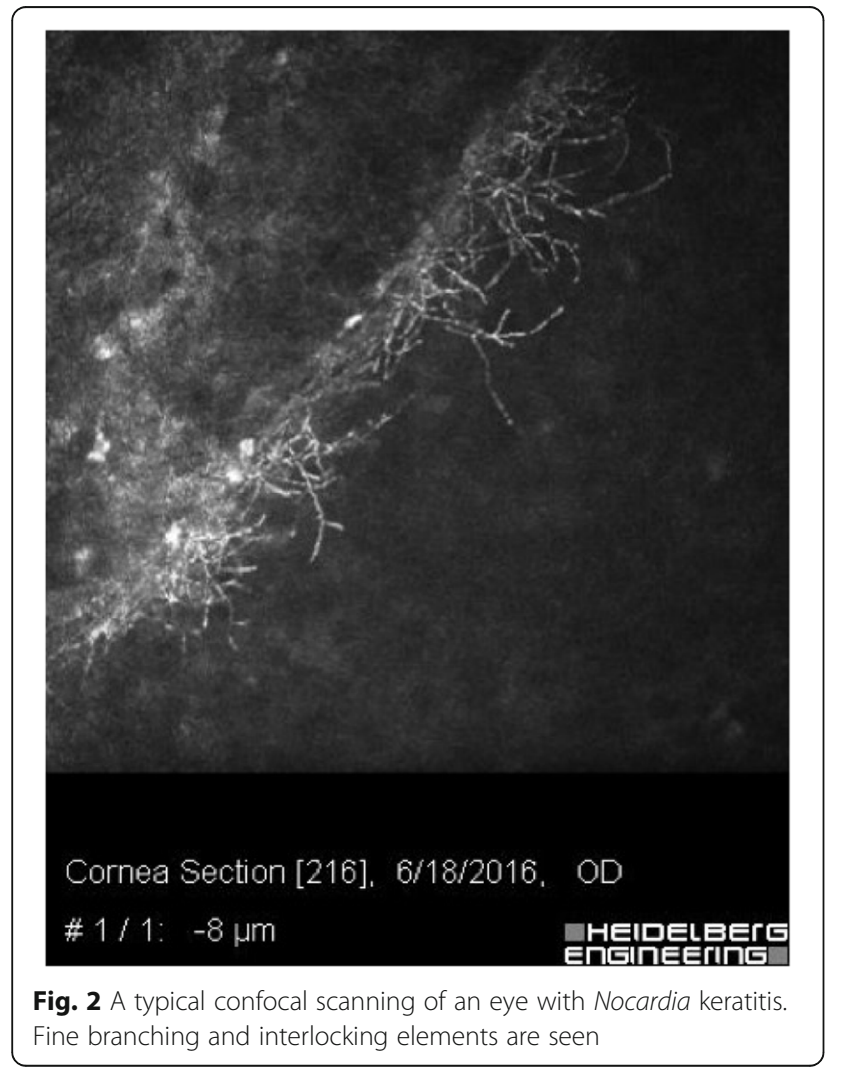

different culture media-growing aerobic and anaerobic bacteria, fungi, and acanthamoeba [6].

\section{Microscopic evaluation}

The collected corneal specimens are smeared, stained, and then examined under a light microscope. Staining methods include Gram stain, Giemsa stain, and 10\% potassium hydroxide with calcofluor white-superior for detecting Nocardia species [20]. Nocardia are beaded Gram-positive, filamentous organisms, weakly acid fast that are best stained with the modified Ziehl-Neelsen or Kinyoun stain method [32] (Fig. 3a). Branching at right angle is a suggestive feature of Nocardia asteroids [33]. Actinomycetes, in contrast to fungi, do not fluoresce under ultraviolet (UV) illumination in a calcofluor white staining. All actinomycetes stain black in the Gomori methenamin staining (GMS). The weakly acid-fast characteristic of Nocardia species distinguishes them from other actinomycetes. Unlike mycobacteria, Nocardia do not resist decolorization with $20 \%$ sulfuric acid on ZeihlNeelsen stain [34]. Histopathological examination reveals scattered stromal necrosis with acute and chronic inflammation [13].

\section{Culture}

Nocardia grow slowly in culture but they are not fastidious. Nocardia species can be cultured on most available non-selective media. The selective media Thayer-Martin agar with antibiotics can increase the yield especially when specimens are contaminated with normal flora [1]. Typically, growth takes 3-5 days on nonselective agars, although longer inoculation period may be required to achieve a size of 5-10 $\mathrm{mm}$ [6]. The filamentous colonies are smooth and moist, and have a chalky, mat or velvety appearance [17] (Fig. 3a and b). The colonies can also exhibit a yellowish color [6]. The filaments will progressively break into coccobacillary elements. Branching may or may not be seen. Nocardia are not a part of the ocular or respiratory normal flora-their isolation is considered significant. 


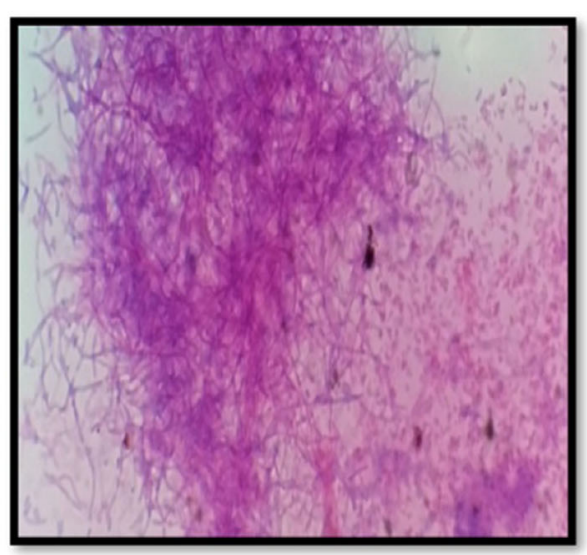

A

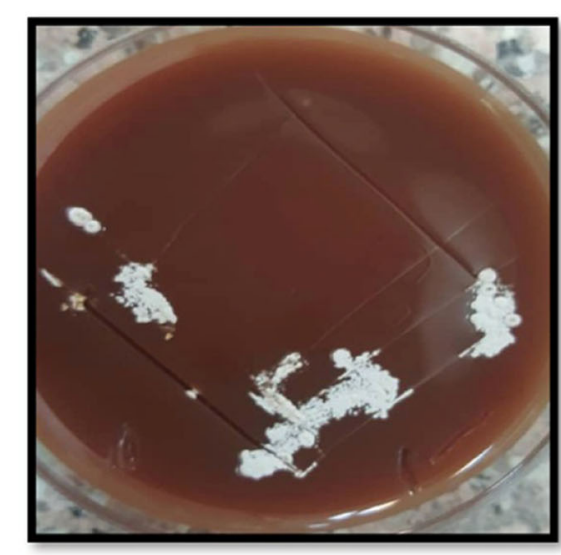

B

Fig. 3 a The modified Ziehl-Neelsen or Kinyoun stain method. Nocardia isolated from a corneal ulcer showing acid-fast filaments (magnification $\times 400$ ). b Blood agar inoculated with corneal scrapings showing white, dry and chalky colonies

\section{Biochemical methods}

Nocardia species can be differentiated by various biochemical tests: hydrolysis of amino acids such as adenine, casein, tyrosine, xanthine, and hypoxanthine, decomposition of urea, utilization of citrate, production of nitrate reductase, growth at $45^{\circ} \mathrm{C}$, and producing acid from carbohydrates such as glucose, maltose, lactose, galactose, salicin, xylose, raffinose, arabinose, rhamnose, sorbitol, and sucrose [35]. Conventional methods appear to be unreliable and limited in identifying different Nocardia species. Biochemical tests are time consuming and expertise demanding. Only few Nocardia species, such as N. brasiliensis, N. farcinica, and N. pseudobrasiliensis can be accurately identified by biochemical tests [35].

\section{Molecular diagnosis}

Molecular diagnostic methods, including gene sequencing, have identified numerous new species of Nocardia. Brown et al. introduced a 314-bp DNA fragment tailored to identify N. farcinia by PCR assay [36]. Patel et al. investigated the ability of 500-bp $16 \mathrm{~S}$ rRNA gene sequencing to identify most species of aerobic actinomycetes [37]. The sensitivity and specificity of this method were reported to be $88 \%$ and $76 \%$, respectively [38]. Though, the ATCC 19247 strain sequence of $N$. asteroides does not identify any taxa with clinical importance. The PCRbased hsp65 gene sequencing can isolate the species from ocular Nocardiosis [39]. This sequencing can be helpful in identifying $N$. arthritidis-commonly involved in Nocardia keratitis, and N. neocaledoniens-a causative agent of conjunctivitis. Recently, the use of nextgeneration sequencing (NGS) has been suggested for timely diagnosis of nocardiosis [40]. Nucleic acid amplification methods are expensive and rarely available.
Their usage is limited for atypical and challenging cases or for investigation purposes.

\section{Treatment}

Traditionally, Sulfonamides were the treatment of choice for Nocardia keratitis. Trimethoprim-sulfamethoxazole showed superiority to trimethoprim alone or sulfacetamide in clearance of Nocardia [41]. Several antibiotics were implemented in the treatment of ocular Nocardiosis including topical chloramphenicol [27], gentamicin [42], polymyxin B sulfate/trimethoprim, amikacin, ciprofloxacin, levofloxacin, moxifloxacin, ofloxacin, gatifloxacin [28], tobramycin, and imipenem [15], and oral clarithromycin [17]. Resistance to tobramycin [43], ciprofloxacin [43], trimethoprim [44], vancomycin [19], clarithromycin [45], and amikacin $[1,46]$ have been reported. Currently, amikacin is the treatment of choice for ocular Nocardiosis [45, 46]. Trimethoprim-sulfamethoxazole can be added to the therapy. Adjuvant use of corticosteroid in bacterial keratitis including Nocardia keratitis is still controversial. The Steroids for Corneal Ulcers Trial (SCUT), a randomized multicenter clinical trial, compared prednisolone sodium phosphate $1 \%$ to placebo as adjuvant therapies for bacterial corneal ulcers treatment. After 3-month, the authors didn't find any significant difference in the best corrected visual acuity (BCVA) of both groups [47]. The eyes with Nocardia keratitis treated with corticosteroids showed an average of $0.4 \mathrm{~mm}$ increase in the infiltrate or scar size after 3-month $(P=0.03)[3,47]$. Nocardia keratitis has a good prognosis if treated promptly. Lalitha et al. demonstrated that the best visual outcome in Nocardia keratitis will be achieved if treatment begins within 15 days of ulcer onset [9]. Delays in diagnosis and treatment of Nocardia keratitis result in irreversible scarring and necessitate a surgical management. Therapeutic lamellar keratectomy, 
penetrating keratoplasty, and conjunctival flap are some of the surgical options [6]. Rahimi et al. used an adjuvant amniotic membrane transplantation (AMT) for persistent epithelial defect (PED) and deep corneal vascularization in Nocardia keratitis extending to limbus [48]. PED resolved, yet corneal vascularization persisted despite AMT therapy. Recently, Shah et al. reported a case of multi-drug resistant Nocardia keratitis resistant to both amikacin and cotrimoxazole [49]. The authors treated the ulcer with femtosecond lamellar keratectomy, thus removing the infected tissue and increasing the drug delivery to the ulcer. Administration of polymyxin $\mathrm{B} /$ trimethoprim and tobramycin was successful in treating the ulcer with minimal residual scarring.

\section{Conclusions}

Nocardia is a rare cause of keratitis. The SCUT study described Nocardia as the third causative agent of bacterial keratitis [47]. One study reported $N$. arthritidis and $N$. asteroides as the most important causative species of Nocardia keratitis, respectively [39]. Nocardia grow slowly in culture medium. Confocal microscopy and nucleic acid amplification are the newer diagnostic tools for Nocardia. Several antibiotics were used in the treatment of Nocardia keratitis, but fortified amikacin eyedrop remains the current best choice. Early diagnosis and treatment are essential to preserve good visual outcome; irreversible scarring may warrant additional surgical options. Adjuvant topical steroids should be avoided in the management of Nocardia keratitis.

\section{Abbreviations \\ PRK: Post Photorefractive Keratectomy; LASIK: LAser in SItu Keratomileusis; CED: Corneal Epithelial Defect; KPs: Keratic Precipitates; UV: Ultra Violet; GMS: Gomori Methenamin Staining; NGS: Next-Generation Sequencing; SCUT: Steroids for Corneal Ulcers Trial; BCVA: Best Corrected Visual Acuity; AMT: Amniotic Membrane Transplantation; PED: Persistent Epithelial Defect}

\section{Acknowledgements}

Not applicable.

\section{Authors' contributions}

All authors contributed to the research and review of literatures. All authors contributed to the writing of the article. The authors read and approved the final manuscript.

\section{Funding}

This research did not fund by any funding agency in the public, commercial or not-for- profit sectors.

\section{Availability of data and materials}

Not applicable.

\section{Ethics approval and consent to participate}

Not applicable.

\section{Consent for publication}

Not applicable.

\section{Competing interests}

The authors declare that they have no conflicts of interest.

\section{Author details}

${ }^{1}$ Ocular Trauma and Emergency Department, Farabi Eye Hospital, Tehran University of Medical Sciences, Tehran, Iran. ${ }^{2}$ Department of Medical Parasitology and Mycology, School of Public Health, Tehran University of Medical Sciences, Tehran, Iran.

Received: 18 September 2020 Accepted: 23 November 2020

Published online: 02 December 2020

\section{References}

1. Johansson B, Fagerholm P, Petranyi G et al (2017) Diagnostic and therapeutic challenges in a case of amikacin-resistant Nocardia keratitis. Acta Ophthalmol 95(1):103-105

2. Behaegel J, Dhubhghaill SN, Koppen C (2018) Diagnostic challenges in Nocardia keratitis. Eye Contact Lens 44(1):370-372

3. Lalitha P, Srinivasan M, Rajaraman R et al (2012) Nocardia keratitis: clinical course and effect of corticosteroids. Am J Ophthalmol 154(6):934-939 e1

4. Sridhar MS, Sharma S, Reddy MK et al (1998) Clinicomicrobiological review of Nocardia keratitis. Cornea 17(1):17-22

5. Sridhar MS, Gopinathan U, Garg P, Sharma S, Rao GN (2001) Ocular nocardia infections with special emphasis on the cornea. Surv Ophthalmol 45(5):361-378

6. Lalitha P (2009) Nocardia keratitis. Curr Opin Ophthalmol 20(4):318-323

7. Conville PS, Brown-Elliott BA, Smith T, Zelazny AM (2018) The complexities of Nocardia taxonomy and identification. J Clin Microbiol 56(1):e01419-17. https://doi.org/10.1128/JCM.01419-17.

8. Conville PS, Witebsky FG (2011) Nocardia, rhodococcus, gordonia, actinomadura, streptomyces, and other aerobic actinomycetes. In: Manual of clinical microbiology, 10th edn. American Society of Microbiology, pp 443-471

9. Lalitha P, Tiwari M, Prajna NV et al (2007) Nocardia keratitis: species, drug sensitivities, and clinical correlation. Cornea 26(3):255-259

10. Upadhyay MP, Karmacharya PC, Koirala S et al (1991) Epidemiologic characteristics, predisposing factors, and etiologic diagnosis of corneal ulceration in Nepal. Am J Ophthalmol 111(1):92-99

11. DeCroos FC, Garg P, Reddy AK, Sharma A, Krishnaiah S, Mungale M et al (2011) Optimizing diagnosis and management of nocardia keratitis, scleritis, and endophthalmitis: 11-year microbial and clinical overview. Ophthalmology 118(6):1193-1200

12. Srinivasan M, Gonzales CA, George C et al (1997) Epidemiology and aetiological diagnosis of corneal ulceration in Madurai, South India. Br J Ophthalmol 81(11):965-971

13. Javadi MA, Kanavi MR, Zarei-Ghanavati S et al (2009) Outbreak of Nocardia keratitis after photorefractive keratectomy: clinical, microbiological, histopathological, and confocal scan study. J Cataract Refract Surg 35(2):393-398

14. Faramarzi A, Feizi S, Javadi MA et al (2012) Bilateral nocardia keratitis after photorefractive keratectomy. J Ophthalmic Vis Res 7(2):162

15. Patel NR, Reidy JJ, Gonzalez-Fernandez F (2005) Nocardia keratitis after laser in situ keratomileusis: clinicopathologic correlation. J Cataract Refract Surg 31(10):2012-2015

16. Troumani Y, Touhami S, Beral L, David T (2015) Corneal Nocardiosis mistaken for fungal infection. J Fr Ophtalmol 38(1):e7-e9

17. Gieger A, Waller S, Pasternak J (2017) Nocardia Arthritidis keratitis: case report and review of the literature. Nepal J Ophthalmol 9(18):91-94

18. Hoffman PM, Poon A, Snibson GR (2005) Nocardia keratitis in a contact lens wearer. Arch Ophthalmol 123(12):1759

19. Mizota A, Haki K, Shiina C, Tanaka M, Nakazawa T, Yazawa K et al (2007) The first case of keratitis caused by Nocardia exalbida. Int Ophthalmol 27(5):333336

20. Bharathi MJ, Ramakrishnan R, Vasu S et al (2003) Nocardia asteroides keratitis in South India. Indian J Med Microbiol 21(1):31

21. Prieto-Borja L, García-Coca M, Ustratova I, Alejandre NA (2017) Keratitis due to Nocardia nova after cataract surgery. Enferm Infecc Microbiol Clin 35(1):57-58

22. Jain V, Dua N, Sridhar MS, Sharma S (2006) Nocardia keratitis in a corneal graft. Eye (Lond) 20(12):1385-1386

23. Liu XN, An N, Wu J et al (2014) Corneal ulcer caused by nocardia brasiliensis in a patient with diabetes. Int J Ophthalmol 7(2):381

24. Bhusal B, Kumar A, Prajna MV, Srinivasan M (2016) Nocardia keratitis following penetrating corneal injury treated with topical ampicillin. Nepal J Ophthalmol 8(15):82-86

25. Trichet E, Cohen-Bacrie S, Conrath J, Drancourt M, Hoffart L (2011) Nocardia transvalensis keratitis: an emerging pathology among travelers returning from Asia. BMC Infect Dis 11(1):296 
26. Mascarenhas J, Srinivasan M, Chen M, Rajaraman R, Ravindran M, Lalitha P et al (2012) Differentiation of etiologic agents of bacterial keratitis from presentation characteristics. Int Ophthalmol 32(6):531-538

27. Matuska S, Rama P, Cavallero A et al (2006) Nocardia keratitis: a case report. SAGE Publications Sage UK, London

28. Mittal V, Fernandes M (2012) Cotrimoxazole-resistant Nocardia sclerokeratitis: effective therapy with fourth-generation fluoroquinolones. Can J Ophthalmol 47(6):e58-e60

29. Vaddavalli PK, Garg P, Sharma S, Thomas R, Rao GN (2006) Confocal microscopy for Nocardia keratitis. Ophthalmol 113(9):1645-1650

30. Hau SC, Dart JK, Vesaluoma M, Parmar DN, Claerhout I, Bibi K et al (2010) Diagnostic accuracy of microbial keratitis with in vivo scanning laser confocal microscopy. Br J Ophthalmol 94(8):982-987

31. Eggink CA, Wesseling P, Boiron P, Meis J (1997) Severe keratitis due to Nocardia farcinica. J Clin Microbiol 35(4):999-1001

32. McMurray DN (1996) Mycobacteria and nocardia. In: Medical microbiology, 4th edn. University of Texas Medical Branch at Galveston

33. Ferry AP, Font RL, Weinberg RS, Boniuk M, Schaffer CL (1988) Nocardial endophthalmitis: report of two cases studied histopathologically. $\mathrm{Br} \mathrm{J}$ Ophthalmol 72(1):55-61

34. Weed LA, Andersen HA, Good CA, Baggenstoss AH (1955) Nocardiosis: clinical, bacteriologic and pathological aspects. N Engl J Med 253(26):1137-1143

35. Brown-Elliott BA, Brown JM, Conville PS, Wallace RJ (2006) Clinical and laboratory features of the Nocardia spp. based on current molecular taxonomy. Clin Microbiol Rev 19(2):259-282

36. Brown JM, Pham KN, McNeil MM, Lasker BA (2004) Rapid identification of Nocardia farcinica clinical isolates by a PCR assay targeting a 314-base-pair species-specific DNA fragment. J Clin Microbiol 42(8):3655-3660

37. Patel JB, Wallace RJ Jr, Brown-Elliott BA, Taylor T, Imperatrice C, Leonard DG et al (2004) Sequence-based identification of aerobic actinomycetes. J Clin Microbiol 42(6):2530-2540

38. Rouzaud C, Rodriguez-Nava V, Catherinot E, Méchaï F et al (2018) Clinical assessment of a Nocardia PCR-based assay for diagnosis of Nocardiosis. J Clin Microbiol 56(6):e00002-e00018

39. Yin X, Liang S, Sun X, Luo S (2007) Ocular nocardiosis: HSP65 gene sequencing for species identification of Nocardia spp. Am J Ophthalmol 144(4):570-573

40. Weng S-S, Zhang H-Y, Ai J-W, Gao Y et al (2020) Rapid detection of Nocardia by next-generation sequencing. Front Cell Infect Microbiol 10:13

41. Lee LH, Zaidman GW, Van Horn K (2001) Topical bactrim versus trimethoprim and sulfonamide against nocardia keratitis. Cornea 20(2):179-182

42. Sridhar MS, Sharma S, Garg P, Rao GN (2001) Treatment and outcome of Nocardia keratitis. Cornea 20(5):458-462

43. Sharma N, O'Hagan S (2016) The role of oral co-trimoxazole in treating Nocardia farcinica keratitis-a case report. J Ophthalmic Inflamm Infect 6(1):23

44. Gonzalez A, Fakhar K, Gubernick D, Tuli S (2014) Scleritis caused by in vitro linezolid-resistant Nocardia asteroides. Case Rep Ophthalmol Med 2014: 326957

45. Glupczynski Y, Berhin C, Janssens M, Wauters G (2006) Determination of antimicrobial susceptibility patterns of Nocardia spp. from clinical specimens by Etest. Clin Microbiol Infect 12(9):905-912

46. Patel R, Sise A, Al-Mohtaseb Z, Garcia N, Aziz H, Amescua G et al (2015) Nocardia asteroides keratitis resistant to Amikacin. Cornea 34(12):1617-1619

47. Srinivasan M, Mascarenhas J, Rajaraman R, Ravindran M, Lalitha P, Glidden DV et al (2012) Corticosteroids for bacterial keratitis: the steroids for corneal ulcers trial (SCUT). Arch Ophthalmol 130(2):143-150

48. Rahimi F, Aghsaie Fard M, Soltani Mogaddam R (2009) A case of amniotic membrane transplantation in non-healing Nocardia asteroides keratitis. J Ocul Biol Dis Infor 2(1):37-39

49. Shah P, Zhu D, Culbertson WW (2017) Therapeutic femtosecond laserassisted lamellar keratectomy for multidrug-resistant Nocardia keratitis. Cornea 36(11):1429-1431

\section{Publisher's Note}

Springer Nature remains neutral with regard to jurisdictional claims in published maps and institutional affiliations.

\section{Submit your manuscript to a SpringerOpen ${ }^{\circ}$ journal and benefit from:}

- Convenient online submission

- Rigorous peer review

- Open access: articles freely available online

- High visibility within the field

- Retaining the copyright to your article

Submit your next manuscript at $>$ springeropen.com 